\title{
LA PROLIFERACIÓN DE RETRIBUCIONES EN EL PARLAMENTO EUROPEO
}

POR

\author{
DR. HANS HERBERT VON ARNIM* \\ Catedrático de la Universidad Alemana de Ciencias \\ de la Administración de Espira (Alemania) \\ DR. ÁNGEL IGLESIAS ALONSO** \\ Profesor Titular de EU de la Universidad Rey Juan Carlos de Madrid
}

\section{INTRODUCCIÓN}

Durante los últimos 25 años, los diputados europeos han aprobado a su favor amplias disposiciones relativas al reembolso de sus gastos y a pensiones de jubilación, invalidez y para familiares, de todo lo cual resulta una carga de cientos de millones de euros en el presupuesto de Bruselas. Las regulaciones al respecto, muy poco conocidas en su mayor parte, que se hallan recogidas en las 63 páginas de la "Normativa sobre reembolso de gastos y pago de dietas a los diputados del Parla-

* Profesor de Ciencia Política y Teoría Constitucional en la Escuela Superior de Ciencias de la Administración de Speyer (Alemania). El presente trabajo se enmarca en el proyecto "Financiación de la actividad política en la Unión Europea», dirigido por él y desarrollado en el Instituto de Investigación de dicha Escuela Superior. El autor agradece a Martin Schurig el valiosísimo apoyo prestado para la preparación de este trabajo.

* Además de haber completado y adaptado este trabajo, ha realizado su traducción del alemán al castellano. 
mento Europeo" ${ }^{1}$, son decretadas únicamente por la Mesa del Parlamento $^{2}$. En principio, no aparecen en tal normativa las cantidades a percibir en cada caso, sino que o bien se las vincula a las remuneraciones de los funcionarios por medio de complicadas claves de cálculo, quedando así dinamizadas, o bien la Mesa las determina de año en año independientemente. Dicha Mesa la forman el Presidente del Parlamento, los 14 Vicepresidentes $y$, con voz pero sin voto, los cinco llamados cuestores $^{3}$. De este modo, el proceso decisorio se evade por completo al Pleno, al conocimiento público, al Consejo de Ministros y a la Comisión Europea.

No obstante, la retribución propiamente dicha de los europarlamentarios se paga a cargo de los presupuestos nacionales, por lo que se basa en disposiciones legales también nacionales. Conforme a ello, los representantes populares presentes en Estrasburgo quedan, por lo que hace a sus retribuciones, equiparados en principio a los respectivos diputados nacionales. Los eurodiputados alemanes, por ejemplo, perciben -como sus colegas del Bundestag- $7.009 €$ al mes, y los austriacos, $8.750 €$; los representantes populares italianos perciben $10.975 €$; los españoles, $3.056 €$; los ingleses, (como promedio) $7.107 €$. Los europarlamentarios franceses tienen una asignación base de $5.205 €^{4}$. Igualmente,

1 PE 113.116/BUR/rev. XVII/02, 2004, no publicado. Cuando los diputados europeos, en el debate público acerca de, por ejemplo, su dieta de estancia (véase más abajo, ap. II.1) o el reembolso de sus gastos de viaje (II.2), se remiten continuamente a las disposiciones correspondientes del "Reglamento del Parlamento" Se están refiriendo a la "Normativa sobre reembolso de gastos y pago de dietas». El Reglamento se limita a facultar para elaborar una normativa de este tipo (véase la nota siguiente), la cual, por supuesto, no podrá contravenir derecho comunitario de rango superior.

[N.d.T.: En el caso de esta normativa no publicada (y en el de dos sentencias del TJE tratadas más abajo, de los años 1981 y 1984), el traductor no ha podido acceder, si las hay, a las versiones oficiales de la UE en español, por lo cual ha traducido él mismo las citas a partir del texto original del presente artículo. El Reglamento del Parlamento, en cambio, y los demás documentos de la UE manejados por el autor aparecen en esta traducción citados según la versión oficial de la UE al español.]

2 Art. 5 del Reglamento del Parlamento: "La Mesa regulará el reembolso de los gastos y el pago de las dietas de los diputados". Cfr. además el art. 22.2: "La mesa resolverá los asuntos económicos, de organización y administrativos que afecten a los diputados, a la organización interna del Parlamento, a su secretaría y a sus órganos".

3 Art. 21 del Regl.

${ }^{4}$ Los holandeses son los únicos que, desde 1996, han congelado las remuneraciones de sus diputados europeos, mientras que aumentaban solamente las de sus parlamentarios nacionales. 
la pensión de jubilación de los diputados de la UE se corresponde con la de sus respectivos colegas nacionales, en lo cual Italia y Francia constituyen una excepción (más detalles sobre ello más abajo, ap. III, 1a).

Con la propuesta de Estatuto de los diputados europeos, que el Parlamento había aprobado en el año $2003^{5}$, se pretendía unificar al alza las retribuciones y las pensiones de jubilación de los diputados europeos. La intención era que todos los diputados, fuera cual fuese su país de procedencia, ingresaran la mitad del sueldo base de un juez del Tribunal de Justicia de las Comunidades Europeas (TJE), que actualmente asciende a $18.106 €$ mensuales: $9.053 €$, pues, a los que se añadirían elevadas pensiones tras la jubilación, en caso de invalidez y viudedad. De este modo, las disposiciones sobre pensiones decretadas por la Mesa quedarían en parte fuera de vigor $^{6}$, y en parte seguirían siendo de aplicación, pero solamente ya para quienes hasta la fecha hubieran pertenecido al Parlamento 7 . Mientras tanto, todo lo relativo al reembolso de gastos a cargo de los presupuestos de la UE no iba a estar contemplado en el Estatuto, sino que habría coexistido con él, y habría sido regulado en lo sucesivo por la Mesa del Parlamento ${ }^{8}$. De cualquier modo, el Estatuto fue rechazado en el Consejo de Ministros el 26 de enero de 2004, por la oposición de Alemania, Francia, Austria y

${ }^{5}$ Con fecha de 3 de junio, el Parlamento Europeo aprobó un Estatuto de los Diputados para sus miembros, decisión que confirmó tras el dictamen de la Comisión Europea del 4-jun-2003. Al objeto de convencer al Consejo de Ministros para su adopción, necesaria en virtud del art. 190 del Tratado Constitutivo de la CE, el Parlamento realizó ciertas concesiones en una resolución de fecha 17-dic-2003.

${ }^{6}$ Anexos I y ll de la Normativa sobre reembolso de gastos y pago de dietas.

7 Art. 35 de la propuesta de Estatuto de los diputados.

${ }^{8}$ Según el art. 27.1 de la propuesta del citado Estatuto, los diputados tendrán "derecho al reembolso de los gastos en los que hubieran incurrido en el ejercicio de su mandato". Según el punto 2, el Parlamento determinará "en qué casos puede efectuarse el reembolso mediante un importe a tanto alzado". El art. 28.1 concede a los diputados el "derecho a recibir la asistencia de colaboradores personales libremente seleccionados por ellos". El desarrollo concreto de estas disposiciones queda expresa y exclusivamente en manos del Parlamento (arts. 27.3, 28.2, y también art. 11.4) y, con ello, en manos de la Mesa. Se debe partir, por lo tanto, de que tampoco en el caso de una futura aprobación del Estatuto sufrirán ninguna restricción las disposiciones sobre reembolso de gastos vigentes hasta la fecha — con la única excepción del reembolso de gastos por viajes en avión (véase sobre ello más abajo el ap. II.2)-. Aunque sectores interesados no cesen de afirmar que con la aprobación del Estatuto de los diputados quedarían también automáticamente eliminados abusos de la normativa de dietas como los que se producen con la dieta de estancia, tal afirmación carece de cualquier fundamento. 
Suecia ${ }^{9}$. De modo que seguirá vigente en su integridad la "Normativa sobre reembolso de gastos y pago de dietas" elaborada por la Mesa (incluyendo sus disposiciones relativas a las pensiones). En lo que sigue, sus elementos más importantes serán objeto de breve exposición y comentario.

\section{REEMBOLSO DE GASTOS}

\section{Dieta de estancia}

Los diputados europeos perciben una dieta de estancia diaria por valor de $262 €$ libres de impuestos, la cual, destinada ante todo a la manutención y pernocta en Estrasburgo y Bruselas y a los desplazamientos en esta zona, resulta siempre satisfecha en su integridad, independientemente de los gastos efectivamente habidos ${ }^{10}$. En principio, la dieta de estancia se abona por aquellos días de sesión del Parlamento Europeo, de sus comisiones y de sus restantes órganos en los que el diputado "demuestre» ${ }^{11}$ su participación mediante firma. Lo mismo se aplica a los "días-puente» entre los días de sesión, y al llamado "viernes libre" siempre que el diputado haya participado en una sesión oficial el día precedente ${ }^{12}$. Lo usual es que la dieta de estancia ascienda a un total mensual de en torno a los $3.500 €$. Quien suela recurrir a alojamientos baratos o alquile un apartamento en Bruselas (donde tienen lugar el grueso de las sesiones), tal como parece que hace la gran mayoría de los diputados ${ }^{13}$, o quien deje que los grupos de presión (lobby groups) le inviten a comer, se ahorrará así una gran porción de

9 La negativa de estos cuatro estados impidió que se formara la mayoría cualificada necesaria, de manera que la cuestión impositiva, que requiere unanimidad, no pudo ser ya tratada en el Consejo de Ministros. Véase sobre ello Hans Herbert von Arnim: 9053 Euro Gehalt für Europaabgeordnete? Der Streit um das europäische Abgeordnetenstatut, 2004.

10 Art. 11 y ss. de la Normativa sobre reembolso de gastos y pago de dietas. Los artículos que en lo que sigue serán citados sin referencia más detallada pertenecen igualmente a esta normativa.

11 Art. 1.5.

12 La dieta de estancia se abona también por la participación en sesiones de comisiones del parlamento nacional en las que se haya requerido al diputado (art. 12.5). Por la participación autorizada en cursos de idiomas se paga media dieta de estancia (art. 12.4).

13 Así lo afirma el diputado europeo holandés Michiel van Hulten (Carta al Presidente del Parlamento Europeo, de 1 de enero de 2003). 
la dieta de estancia, con lo que le quedarán unos considerables ingresos adicionales libres de impuestos. Además, también podrá reclamar su dieta quien, por ejemplo, se halle desempeñando su segunda profesión ejerciendo acciones de lobby, ya que la demostración de que el diputado ha estado dedicado a las labores de su mandato es manejada de una manera más que laxa.

La procedencia de la dieta de estancia queda "demostrada" por el hecho de que el diputado haya viajado a Bruselas o Estrasburgo a comienzos de semana y emprendido luego el regreso el jueves o el viernes, para lo cual ha de haber presentado factura por los gastos de viaje y haber firmado las listas de asistencia dispuestas al efecto ${ }^{14}$. La procedencia de la dieta de estancia para los viernes sin sesión queda igualmente "demostrada" mediante firma ${ }^{15}$, lo cual se aplica también a sesiones que hayan sido desconvocadas ${ }^{16}$. El Tribunal de Cuentas ha hecho al respecto una observación tan lapidaria como precisa: "La firma de los registros de asistencia no permite determinar la participación efectiva de los diputados en los trabajos del Parlamento " ${ }^{17}$. La actual normativa, así pues, promueve directamente dicho abuso. Por ello, los eurodiputados holandeses se han comprometido en su Código de Conducta a reclamar sólo la dieta de estancia correspondiente a las jornadas dedicadas de hecho al trabajo parlamentario ${ }^{18}$.

En cuanto al cálculo de la dieta de estancia debe también tenerse en cuenta que suele ser abonada contando un día adicional más respecto a las pernoctas habidas. A esto se añade que desde hace algún tiempo se entregan a los diputados bonos para taxi, aunque entre los fines de la dieta de estancia se contaba también, de hecho, el de cubrir los gastos de transporte en la zona ${ }^{19}$.

14 Art. 11.1, letras a, b.

15 Así se afirma en el art. 11.1, letra d. Por tanto, la crítica del eurodiputado austriaco Hans-Peter Martin contra los diputados que firman las listas de asistencia los viernes sin sesión por la mañana, para percibir la dieta de estancia, pero inmediatamente emprenden el viaje, hay que dirigirla contra lo dispuesto por el artículo citado, al cual se remiten los diputados para justificar su proceder.

16 Nota de prensa del eurodiputado austriaco Hans-Peter Martin, de 11-feb2004.

17 Informe Especial 10/98 del Tribunal de Cuentas Europeo (98/C 243), p. 1 [4], epígrafe 1.21.

${ }_{18}$ Code of Conduct for Dutch Members of the European Parliament, 14-may1999 , punto 5 .

19 van Hulten (op.cit., nota 13). 
La dieta de estancia queda reducida a la mitad para cualquier día de sesión durante el cual el diputado se haya ausentado de más de la mitad de todas las votaciones nominales. Las votaciones se celebrarán "siempre los martes, miércoles y jueves de sesión en Estrasburgo, y el segundo día de sesión en Bruselas ${ }^{20}$. Pero esta norma podría quizá ser una razón para la singular práctica del Parlamento Europeo de bloquear las votaciones pues, una vez debatida la materia en cuestión, estas no se celebran inmediatamente, tal como exigiría un orden natural de las cosas (y tal como, por ejemplo, sucede en el mismo Bundestag o Cámara Baja alemana). Antes bien, las votaciones sobre propuestas de los más diferentes tipos son aplazadas en conjunto hasta una fecha determinada, y tienen lugar entonces una tras otra en un maratón del voto. De esta manera, los diputados pueden evitar deducciones en su dieta de estancia incluso cuando no hayan asistido ni por un solo momento al debate de la materia votada.

\section{Reembolso de los gastos de viaje}

En lo que hace a los vuelos a Estrasburgo o Bruselas ${ }^{21}$, son reembolsados los gastos correspondientes al pasaje más caro de clase turista22. Tal importe, por ejemplo en un vuelo de ida y vuelta BerlínBruselas, asciende a casi $1000 €$, que le son entregados íntegramente al diputado aun en el caso de que haya contratado un vuelo más barato, pongamos que por $200 €$. Estos gastos, al que todavía se añade una llamada "Dieta global de distancia» ${ }^{23}$ que, según el número de kilómetros, asciende a entre 112 y $558 €$, puede aportar a los diputados alemanes cerca de $30.000 €$ anuales $^{24}$, no sujetos a tributación alguna.

Cualquier persona corriente que presente factura por unos costes de viaje demasiado altos sabe que le amenaza una demanda. No les ocurre así a los eurodiputados. El Parlamento se ha dotado de una normativa que invita directamente al engaño a la vez que lo legaliza ${ }^{25}$.

20 Art. 11.4.

21 Art. 1, ss.

22 Art. 2.2.a,, y también anot. 4.

23 Art. 2.2, c.

${ }^{24}$ Cfr. por ejemplo Focus de 4-ago-2003, p. 156.

25 Muy clara ha sido también la toma de postura del Secretario de Estado inglés para Asuntos Europeos, Denis McShane, acerca de las prácticas con los gastos de viaje: "No creo que se pueda argumentar a favor de algo que es fraudulento e inaceptable. No se puede considerar simplemente que esto sea una manera de resolver 
Por lo demás, también se puede presentar factura por los viajes considerándolos realizados en automóvil. No se comprueba si el diputado ha viajado de hecho o bien ha pasado el fin de semana en Bruselas dedicándolo a asuntos privados, basta una declaración personal. Y, en tal caso, dispondrá de una dieta por kilometraje de 0'67 € por cada uno de los primeros $500 \mathrm{~km}$. y 0'28 € por cada uno de los siguientes del trayecto.

La Mesa modificó la normativa sobre el reembolso de gastos de viajes en avión en virtud de una decisión de 28 de Mayo de 2003. Dicha modificación debía entrar en vigor a la vez que el proyectado Estatuto de los diputados, pero, de momento, tras haber sido este rechazado, queda suspendida. $Y$, sea como fuere, la nueva normativa parece ofrecer también sus propios problemas. Hasta ahora, los diputados estaban autorizados a presentar factura solo por unrestricted normal fare en clase turista; en el futuro, se pretende que puedan presentar factura por pasajes en primera clase, mediando presentación de justificantes, lo cual es de prever que resulte para el contribuyente aun más caro de lo que ha sido hasta ahora. Tampoco puede entenderse cómo es que, cuando se trata de ahorrar gastos en provecho propio, los diputados usen vuelos baratos, y sin embargo ya no tengan que hacer tal cosa cuando el ahorro va en provecho del contribuyente. Aunque lo primero que no puede entenderse es por qué no basta, como hasta la fecha, con los pasajes de unrestricted normal fare de la clase turista, sino que ahora se puede presentar también factura por vuelos en primera clase.

\section{Cantidad global en concepto de gastos}

Por otra parte, todos los diputados de la UE perciben además una cantidad global por gastos de $3.700 €$ mensuales, que está destinada preferentemente para los gastos que su mandato origine en el país de origen y cuyo abono, también, es independiente de los costes que se hayan generado de hecho ${ }^{26}$. En Estrasburgo y Bruselas, los diputados disponen de dietas de estancia, oficinas equipadas, medios de trans-

el problema de lo que los eurodiputados cobran en su marco nacional. La reforma puede hacerse mañana mismo; insto a los eurodiputados para que envíen a los votantes europeos un mensaje claro de que el Parlamento Europeo es el parlamento más limpio del mundo, y para que dejen de abusar de unas dietas de viaje inaceptables e indefendibles». Cit. por Nicola Smith: "MEP Statute fails at financial hurdle», EUPolitix, 26.1.2004.

${ }^{26}$ Art. 13. 
porte, etc. Por lo que respecta a los eurodiputados alemanes, el erario público nacional financia además numerosas partidas de gasto que cubren fines propios de la cantidad global por gastos, de modo que, en muchos casos, resultan de ello unos considerables ingresos adicionales libres de impuestos. Así, el Tribunal Superior de Justicia de Magdeburgo ha hecho constar expresamente que, en el caso que era su competencia juzgar, un eurodiputado alemán — gracias a las prestaciones en especie y demás prerrogativas de las que disfrutaba - tenía a su libre disposición personal casi toda la cantidad global por gastos y toda la dieta de estancia ${ }^{27}$.

En el caso de los eurodiputados de los países de la ampliación, la cantidad global por gastos resulta ya realmente desorbitante. El nivel de ingresos y de precios es muy bajo: en Polonia, el promedio de ingresos mensuales asciende a $438 €$, y en los otros seis de los nuevos miembros se halla por debajo de los $400 €$. El bajo nivel de vida abarata en esa misma proporción los costes del mandato, de manera que estos eurodiputados podrían tener a su libre disposición la parte del león de la cantidad global, en forma de ingresos adicionales libres de impuestos.

\section{Colaboradores}

Los diputados de la UE pueden contratar colaboradores por un importe total de hasta $12.576 €$ mensuales $^{28}$. En el aspecto económico, la evolución de las cargas presupuestarias resultantes de ello es extraordinariamente "dinámica": mientras que en 1980 correspondió a cada diputado un promedio anual de $32.346 €$ en concepto de gastos en colaboradores, en 2002 era ya de $142.731 €$, cuatro veces y media más. Para 2003 se había previsto un aumento a $153.000 €$ por cada diputado (+ 7'2 \%), y para 2004, a $165.396 €(+8 ' 1 \%)$; subida que, como hace constar el Tribunal de Cuentas Europeo, no queda «aclarada por ninguna referencia transparente ${ }^{29}$.

La calidad y el empleo dado a los colaboradores son cuestiones sobre las que nadie pide cuentas. Los diputados no están dispuestos ni siquiera a dar los nombres de todos sus colaboradores - a pesar de

27 Tribunal Superior Administrativo, Magdeburgo, Sentencia de 3-dic-1997 - A 3 S 6/46, p. 28 de la reproducción autográfica..

28 Art. 14, ss.

29 Tribunal de Cuentas Europeo, Informe Especial 10/98 (98/C 243), p. 5. 
que las normas los someten a la estricta obligación de confeccionar y hacer pública una lista con los nombres de sus asistentes ${ }^{30}$ - y ello sucede en especial con los colaboradores destinados a un trabajo en el país de origen. No es raro que se emplee a amigos a expensas de los contribuyentes, ni tampoco a parientes de los que nadie puede saber si su única función es redondear los ingresos familiares o si también prestan una ayuda real al diputado en las labores de su mandato ${ }^{31}$. En la Comisión presidida por Santer se dieron del mismo modo fenómenos de nepotismo (que acabaron siendo una de las causas de su retirada).

También los diputados de los países de la ampliación —a pesar del bajo nivel de ingresos y de precios existente en ellos- tendrán a su disposición una cantidad de hasta $12.576 €$, con la que podrán emplear a un colaborador en Bruselas y a 15 más en su país de origen, según el promedio de ingresos del mismo; de modo que dispondrán de un personal de apoyo que multiplica el de sus colegas occidentales. En los países de la ampliación - a la vista de sus elevados índices parciales de paro y de su bajo nivel de vida - podría llegar a ser especialmente fuerte la tentación de dar empleo pro forma a miembros de la propia familia. ¿Por qué los eurodiputados checos o húngaros no habrían de imitar con todo entusiasmo el modelo que los diputados occidentales vienen proponiendo desde hace años? ¿Resulta completamente impensable un escenario en el que, por ejemplo, los diputados polacos empleen al conjunto de todos sus parientes a expensas del contribuyente?

Igualmente escaso es el control ejercido sobre la posibilidad de que a los colaboradores de los diputados se les destine al trabajo de partido, con lo cual se está favoreciendo la financiación indirecta de los partidos políticos con fondos públicos. En la normativa sobre la nueva financiación europea de los partidos políticos, que entrará en vigor a mediados de 2004, se ha considerado de gran importancia que los pa-

30 Art. 14.9.

31 Martin Banks ("MEPs defend relatives on the payroll», European Voice, 22/28ene-2004) realiza un listado de 15 eurodiputados que dan empleo a cónyuges o familiares a expensas de la UE. Hans Martin Tillack, en Stern, 18-mar-04, informa a su vez sobre la cuantía de las retribuciones a familiares: el diputado británico Robert Atkins pagó a su mujer $8.332 €$; el representante escocés Neil McCormick llegó a pagar a su mujer $10.228 €$.

No existe en el marco europeo una prohibición de dar empleo a miembros de la propia familia, tal como la que está en vigor para los diputados del Bundestag alemán. 
gos a partidos europeos no deben revertir, ni directa ni indirectamente, en provecho de los partidos nacionales ${ }^{32}$. No obstante, el empleo dado a los colaboradores, para los cuales se han aprobado unos fondos públicos diez veces superiores a los destinados a la financiación de los partidos, lleva consigo la posibilidad de convertirse en una auténtica vía libre para el fraude.

Los recursos destinados al partido fortalecen la posición del diputado dentro del mismo, proporcionándole una ventaja poco menos que insuperable de cara a todos los posibles competidores que se le enfrenten en la nominación de candidatos para las elecciones europeas. Y, en el caso de los diputados de los países de la ampliación, si dedican su enorme poder adquisitivo para pagar a compañeros suyos de partido, podrán desde ese momento aumentar verdaderamente su influencia interna en él. Personas concretas cobrarían así un excesivo peso en la organización, amenazando de modo gravísimo el principio de la democracia interna de los partidos políticos.

\section{PENSIONES}

\section{Pensiones de jubilación}

La pensión de jubilación para los diputados de la UE está regulada de ordinario a través de los estados miembros, y es abonada a cargo de sus presupuestos, tomándose aquí también como patrón a los diputados nacionales respectivos (véase lo dicho más arriba, ap. I). De forma paralela, sin embargo, la Mesa del Parlamento Europeo ha creado dos sistemas de pensiones de jubilación, con lo que llegan a darse notorios casos de sobreprestaciones asistenciales, y ello en un momento en el que - a la vista de la situación demográfica y del elevado paro- se ciernen sobre todos los ciudadanos sustanciosos recortes en sus pensiones.

a) Pensión de jubilación complementaria. Desde 1981, existe un sistema complementario a favor de aquellos diputados de la UE a los

32 Véase el art. 7 del Reglamento n. ${ }^{\circ}$ 2004/2003 del Parlamento Europeo y del Consejo, de 4-nov-2003, relativo al estatuto y a la financiación de los partidos políticos a escala europea (ABIEU n. ${ }^{\circ}$ L 2979, 15-nov-2003, pp. 1 ss.): "La financiación de partidos políticos a escala europea con cargo al presupuesto general de la UE o procedente de cualquier otra fuente no podrá utilizarse para financiar directa o indirectamente otros partidos políticos ni, en particular, otros partidos políticos nacionales". 
que su legislación nacional no garantice pensión de jubilación de ningún tipo, o bien garantice sólo una pensión de jubilación más baja que la de sus colegas en el parlamento nacional ${ }^{33}$.

La primera condición se cumple en el caso de los diputados italianos, para los que "en casa" no hay prevista ninguna pensión de jubilación. En lugar de ello, pues, es el contribuyente europeo quien les paga, a través del sistema complementario, la elevadísima pensión de jubilación de la que disfrutan sus colegas en el Parlamento nacional. Con cinco años de mandato habrán adquirido ya derecho a una pensión del $25 \%$ de su asignación, lo cual supone $2.744 €$ mensuales; y tras diez años, a una pensión del $38 \%$, lo cual supone $4.171 €$. A la financiación del sistema contribuyen con una aportación propia del $8^{\prime} 6 \%$ de su asignación; pero la parte del león se paga con recursos de la UE.

La segunda condición atañe a los eurodiputados franceses. La legislación de su país les garantiza tan solo una pensión de jubilación relativamente modesta, mejorada gracias al sistema complementario europeo hasta alcanzar la elevada pensión de los parlamentarios de la Asamblea Nacional. Por esta vía, tras dos periodos legislativos habrán adquirido ya derecho a una pensión del $45 \%$ de su asignación; lo cual supone $3.916 €$. También los diputados franceses prestan una aportación propia, pero esta sólo cubre una pequeña parte de los costes de la pensión.

Este sistema de pensión de jubilación complementaria produce el notable resultado de que los italianos no solamente son, con sus en torno a $11.000 €$, los que perciben la retribución mensual más elevada de todos los diputados de la UE, sino que además el sistema complementario de la UE les financia la pensión de jubilación más elevada, y ello a expensas de los contribuyentes europeos. También los eurodiputados franceses perciben, gracias a los recursos de la UE y tras sólo dos legislaturas, una pensión muy elevada. No puede entenderse, sin embargo, cómo es que los contribuyentes alemanes y de otros países tienen que pagar a los eurodiputados italianos y franceses una pensión que sus países les niegan. Y lo primero que no puede entenderse es que tal pensión, además, sea muchísimo más elevada que la que los países que la pagan garantizan a sus propios diputados nacionales.

b) Pensión de jubilación adicional. Junto a este sistema, existe desde 1990 otro sistema adicional de pensiones de jubilación, accesible a todos los parlamentarios, incluyendo también a aquellos cuya pen-

${ }^{33}$ Anexo III de la Normativa sobre reembolso de gastos y pago de dietas. 
sión esté ya completamente asegurada (sea por normativas nacionales o por el sistema de pensiones de la UE que acabamos de mencionar) ${ }^{34}$. Participan en él en torno a 400 de los actuales 626 diputados; y pasan ya de 100 los perceptores actuales.

La cuantía de la pensión se halla vinculada, por medio de una complicada regla de cálculo, al sueldo base de un juez del TJE, y por lo tanto asciende de año en año. Requisito mínimo es haber pertenecido al Parlamento durante tres años. Por cada año de mandato, el diputado (a fecha de 2004) adquiere derecho a una pensión de $253 €$ mensuales $^{35}$, cantidad pareja al promedio de ingresos en muchos países de la ampliación. Un periodo legislativo de cinco años proporciona, así pues, una pensión de $1.625 €$ mensuales, pagadera en principio a partir de cumplido el $60 .^{\circ}$ año de vida. Es una cantidad superior a la que percibirán como asignación la mayoría de los eurodiputados en activo elegidos en los nuevos estados miembros, con lo que, tras su entrada en la UE, se producirá una absurda relación distorsionada entre ingresos y pensión de jubilación. Habiendo ejercido 20 años de mandato se habrá alcanzado la cuantía máxima de la pensión, $5.060 €$ mensuales, cifra que eclipsa incluso la asignación de muchos diputados en activo elegidos en los estados miembros más antiguos. Los costes están financiados en un tercio con las contribuciones de los parlamentarios ${ }^{36}$, y en dos tercios por el Parlamento.

Estas prestaciones asistenciales se añaden además, en casi todos los casos, a la pensión nacional (o a la pensión de la UE complementaria). No suele aplicarse ninguna compensación, de modo que a los beneficiarios les corresponden dos pensiones por un mismo periodo de mandato. En Alemania, en todo caso, está previsto un procedimiento de ajuste.

La cuantía y, además, la duplicidad de las pensiones llevan al absurdo resultado de que, en la mayoría de estados miembros de la UE, las pagas de jubilación de antiguos diputados puedan ser mucho más elevadas que los ingresos de sus colegas en activo.

\footnotetext{
34 Anexo IX.

${ }^{35}$ Cantidad que corresponde al 3'5 \% del sueldo base de un juez en el TJE, que actualmente asciende a $18.016 €$ mensuales. El juez, por su parte, ha de percibir el $112 ' 5 \%$ del sueldo base del funcionario de la UE de rango supremo y con el nivel más alto de antigüedad en el servicio.

${ }^{36}$ Cantidad que asciende en el momento de escribir estas líneas a $942 €$ (es decir, calculada en base al $13 \%$ del $40 \%$ del sueldo base de un juez del TJE).
} 


\section{Pensiones de invalidez y para familiares}

A esto se añade una generosa pensión para el diputado que sufriera incapacidad, y,en caso de su fallecimiento, para sus familiares. Aquí, la financiación recae íntegramente sobre el Parlamento Europeo. Son descontadas del total de la pensión las cantidades cobradas procedentes de pensiones nacionales de invalidez o para los familiares.

De sufrir incapacidad ${ }^{37}$, el diputado percibirá $5.431 €$ mensuales, más $905 €$ por cada hijo a su cargo; por tanto, en caso de tener tres hijos, un total de $8.146 €$. Para eurodiputados, por ejemplo, eslovacos o húngaros, que es de prever vayan a percibir una retribución de en torno a 800 o $900 €$ al mes, la certificación de incapacidad vendría casi a equivaler económicamente, y por cínico que esto pueda sonar, a un premio en la lotería primitiva. Si el/la diputado/a fallece ${ }^{38}$, el cónyuge que le sobreviva percibirá una pensión de viudedad de $4.527 €$ mensuales, que no será compensada con sus ingresos propios, a lo que se añadirán $905 €$ más por cada hijo a su cargo.

\section{VALORACIÓN DE CONJUNTO}

\section{Déficit de control}

Una ojeada rápida lo muestra: en la «Normativa sobre reembolso de gastos y pago de dietas" se dan una serie de abusos intolerables. Además, en muchas de sus partes resulta excesivamente compleja, es poco clara y está formulada de manera apenas comprensible, con numerosas excepciones casuísticas y disposiciones especiales. Si una normativa con tantos defectos ha podido llegar a estar vigente, la única razón posible de ello es que en el proceso existen groseros defectos de control. A este respecto, es claro que siempre que el Parlamento decida sobre asuntos internos, serían de especial importancia unos mecanismos de control efectivos. Tal necesidad de control está subrayada también en el art. 190 del Tratado CE, el cual ordena que, en lo relativo a «el estatuto y las condiciones generales de ejercicio de las funciones" de los diputados, la decisión será tomada por el Pleno del Parlamento y con la intervención del Consejo y de la Comisión. El debate público en el Pleno y la publicación del Estatuto en el Diario Oficial asegurarían ese mínimo de control público que no queda garantizado en las decisiones

\section{Anexo II. \\ 38 Anexol.}


tomadas por la Mesa. Fue por esta misma razón por lo que el Tribunal Constitucional alemán tachó de inconstitucional el que partes de la asignación de los diputados fuesen fijadas tan solo por una mesa parlamentaria ${ }^{39}$. Si, a pesar de ello, es la Mesa la que decide, el diputado individualmente no será responsable directo de unas normativas abusivas, con lo que parece quedar en situación de lavarse las manos en un baño de inocencia política, y todo ello prescindiendo completamente de que los votantes alemanes —en virtud del rígido régimen electoral por listas cerradas - tampoco podrían exigirle responsabilidades en ningún caso. Con la aprobación por parte del Consejo en mayoría cualificada y con la consulta a la Comisión quedan incorporadas en el proceso unas instancias de control adicionales y de particular importancia para evitar abusos de poder. Pero todos estos controles y contrapesos se vienen abajo cuando la Mesa del Parlamento, tal como sucede actualmente, es la única que toma la decisión.

\section{Posible conculcación del art. 190 del Tratado CE y del principio de democracia (Art. 6.1 del Tratado UE)}

Que para la decisión acerca de todas las normativas mencionadas baste un sencillo acuerdo tomado por la Mesa del Parlamento Europeo no es un procedimiento que satisfaga lo previsto al respecto por el Tratado CE. Y, por supuesto, al poseer tal Tratado rango jurídico superior, no pueden contravenirlo ni el Reglamento del Parlamento ni la Normativa sobre reembolso de gastos y pago de dietas en él basada. Frente a esto, el Parlamento Europeo se remite a una sentencia del TJE, de 15-sep-81, relativa a un caso originado en los años 1975/7640. Pero, entre tanto, la situación se ha transformado por completo: pues por entonces los reembolsos de gastos no habían alcanzado, ni por asomo, el volumen actual. Y, sobre todo, no existía aún el art. $190 \mathrm{del}$ Tratado CE, novedad introducida en virtud del Tratado de Amsterdam.

39 Sentencia del Tribunal Constitucional alemán, BVerfGE 40, 296 (327); = NJW 1975, 2331.

40 TJE, col. 1981, 2205, sec. 17 - Lord Bruce of Donington / Eric Gordon Aspen. «Es asunto del Parlamento decidir acerca de qué actividades y viajes de un diputado son necesarios o apropiados para el ejercicio de su cargo y a cuánto han de ascender los gastos necesarios o apropiados para ello. La independencia que el Parlamento tiene otorgada al respecto para poder cumplir su función comprende también la facultad de reembolsar a sus miembros los gastos de viaje y estancia no mediando presentación de cada uno de los justificantes correspondientes, sino sobre la base de una regulación a tanto alzado". 
Este artículo atribuye expresamente y para lo sucesivo al Parlamento Europeo, y concretamente al Pleno del mismo, la competencia de «establecer el estatuto y las condiciones generales de ejercicio de las funciones de sus miembros", disponiendo además que para ello se precisará del dictamen de la Comisión y de la aprobación del Consejo. No se comprende por qué no habría que situar también aquí las regulaciones relativas al reembolso de los gastos originados en el ejercicio del mandato. Además, el "reembolso de gastos" implica en considerable medida unos ingresos, cuya regulación, sin ninguna duda, se halla sometida al procedimiento indicado en el art. 190 del Tratado CE. Finalmente, el principio de democracia, que el art. 6 del Tratado UE consigna de igual modo que lo hacen todos los estados miembros (en Alemania, por ejemplo, en el art. 20 de la Ley Fundamental), exige con carácter imperativo la participación del Consejo o de los Gobiernos representados en él, que a su vez son responsables ante los respectivos parlamentos nacionales democráticamente legitimados. Así lo aclaró, en el caso de Alemania, la sentencia sobre Maastricht emitida por el Tribunal Constitucional alemán en $1993^{41}$. Pero el Parlamento Europeo - a falta de un derecho electoral igual y a falta de una infraestructura democrática como podría ser una opinión pública europea- no posee por sí solo la legitimación democrática suficiente para elaborar normativas de tanto calado como las que su Mesa ha decretado bajo la rúbrica del reembolso de gastos ${ }^{42}$.

Por lo que respecta a las pensiones de jubilación, de invalidez y para familiares, que sin ninguna duda representan ingresos y cuya regulación, por tanto, no se ve afectada desde un principio y bajo ningún concepto por la sentencia arriba mencionada del TJE, resulta claro en cualquier caso que la regulación al respecto ha de ser acordada conforme al art. 190 del Tratado CE, y que no basta para ello con una decisión de la Mesa del Parlamento. El Tribunal de Cuentas Europeo también ha reclamado con especial firmeza una regulación que satisfaga lo establecido en el dicho art. $190^{43}$.

${ }^{41}$ Sentencia del Tribunal Constitucional alemán, BVerfGE 89, 155 (182 y ss.); = NJW 1993 3047; = NVwZ 1994, 53 L.

42 Dictamen del Tribunal Constitucional alemán, BVerfGE 89, 155 (184 y ss.). Véase al respecto también Streinz: EUROPAR, 5. ${ }^{a}$ ed. (2001), sec. 283.a; Huber: Staatswissenschaft und Staatspraxis, 1992, 349 (373); idem: VVDStRL 60 (2001), 194 (236 y ss.).

${ }^{43}$ Tribunal de Cuentas Europeo, Informe Anual sobre el ejercicio económico 2002, 18-nov-2003, epígrafes 9.17 y 9.18 . 
Por todo ello, la Normativa sobre reembolso de gastos y pago de dietas examinada en este trabajo carece del fundamento jurídico exigible.

\section{Irregularidades en el procedimiento}

La pretensión de las normativas acordadas por la Mesa no es sólo reembolsar los gastos originados en el ejercicio del mandato, sino que, en parte, aspiran igualmente a compensar las diferencias de remuneración entre las distintas normativas nacionales. Así, ésta sería la razón de que no se ponga ningún reparo a la hora de reembolsar gastos de pasajes aéreos: si se puede conseguir unos ingresos adicionales libres de impuestos recurriendo a vuelos baratos, la justificación aducida para ello es que se pretende proporcionar una ayuda económica a diputados con ingresos nacionales bajos, por ejemplo españoles (3.056 $€$ al mes), portugueses ( $4.024 €$ ) o finlandeses (4.541 €). La misma justificación se aduce para la dieta de estancia y para la cantidad global por gastos, las cuales posibilitan igualmente unos ingresos adicionales libres de impuestos.

Ahora bien, una argumentación semejante ni es proporcionada ni está fundamentada. No es proporcionada al no poder justificar, por ejemplo, cómo es que también los diputados alemanes, italianos o austriacos participan del disfrute de estas dietas a pesar de las elevadas retribuciones que reciben de sus países. Y, por lo demás, el argumento carece también de base: pues a pie de obra, es decir: en Estrasburgo o en Bruselas, los diputados -independientemente de su retribución nacional, y aun en el caso de que las facturas que presenten sean impecables - tienen cubiertas sus necesidades de modo suficiente e igual para todos, de modo que por esta parte no se precisa compensación alguna. Por lo que respecta a la retribución, y aunque está destinada a la manutención de los diputados (y de sus familias) en sus países de origen, no resulta pertinente una igualación. Mientras que no exista un derecho electoral igual y el estado de los ingresos y el nivel medio de vida de los estados miembros sigan mostrando diferencias tan grandes como sucede actualmente, no habrá ningún motivo que induzca a igualar al alza la retribución que los diputados perciben, precisamente, en sus países de origen. En la mayoría de los estados miembros, ello significaría no solo que los diputados quedarían demasiado lejos de sus electores en cuanto al nivel de ingresos, sino que también el sistema retributivo de la clase política se sumiría en un completo desorden ${ }^{44}$.

${ }^{44}$ Von Arnim: cfr. más arriba, nota 9, pp. 12 ss., 18 ss. 


\section{Dudosa adecuación al principio de buena gestión financiera, de la prohibición de abuso y al principio de justicia tributaria}

Las regulaciones sobre reembolso de gastos, al proporcionar a los diputados abundantes ingresos adicionales libres de impuestos, suponen, desde el punto de vista jurídico, malversación de fondos públicos, y contravienen el principio de buena gestión financiera ${ }^{45}$. En la medida en que las regulaciones pueda afirmarse que aspiran a proporcionar ingresos adicionales, estarán contraviniendo entonces también la prohibición de abuso ${ }^{46}$. Pues parece abusivo, en efecto, que lo que realmente se pretende bajo la rúbrica de una normativa de dietas sea proporcionar a los diputados unos ingresos. ${ }^{47}$. Ambos principios son derecho vinculante de la Unión Europea.

Igualmente, la concesión de pensiones dobles por un mismo periodo de mandato es desproporcionada, contraviene el principio de buena gestión financiera y, en la medida en que se pretenda con ello compensar las diferentes cuantías de las retribuciones en los países de origen, contraviene asimismo la prohibición de abuso.

EI TJE ha confirmado que son contrarias a derecho aquellas regulaciones que "sobrepasen los límites proporcionados de un reembolso de los gastos de viaje y estancia» ${ }^{48}$. Y, aun más allá, planteó al respecto una posible gravación fiscal: «En la medida en que el importe a tanto alzado de las dietas pagadas sea demasiado elevado o realmente se trate en parte de una remuneración encubierta y no de un reembolso de gastos, los estados miembros estarán facultados para someter dichos ingresos a sus impuestos nacionales sobre la renta individual, ya que la remuneración de los parlamentarios no es, en el estado actual del de-

${ }^{45}$ Art. 272.10 y también arts. 248.1, y 274.1 del Tratado CE. Cfr. sobre ello Magiera, en: von Arnim (ed.): Finanzkontrolle im Wandel, 1989, pp. 221-233; Lienbacher, en: Schwarze (ed.): EU-Kommentar, 2000, art. 248, sec. 13; Waldhoff, en: Callies / Ruffert (eds.): EUV / EGV, 2. ${ }^{a}$ ed. (2002), art. 274 de EGV, sec. 1; una exposición general sobre el principio de buena gestión financiera, en: Von Arnim: Wirtschaftlichkeit als Rechtsprinzip, 1988.

${ }^{46}$ Art. 230.2 del Tratado CE.

47 Se considerará que existe desviación de poder en el sentido del art. 230.2 del Tratado CE cuando en razón de indicios objetivos, concluyentes y concordantes pueda darse por sentado que la actuación de un órgano de la UE se ha regido, al menos de manera preferente, por fines distintos a los declarados en dicha acción. Así lo afirma repetidamente la jurisprudencia del TJE, p. ej. col. 1984, 2447 (2465) Lux. El empleo de una regulación sobre reembolso de gastos para incrementar la retribución de los diputados recae, a mi parecer, en esta tipificación.

48 TJE, col. 1981, 2205, sec. 21 - Lord Bruce of Donington / Eric Gordon Aspen. 
recho comunitario, materia de los órganos comunitarios, sino del derecho nacional ${ }^{49}$.

Entre tanto, es cierto que ha entrado en vigor el art. 190 del Tratado CE. No obstante, sobre esta base no ha sido promulgado hasta la fecha ningún Estatuto de los diputados de la UE, y la remuneración de los eurodiputados no ha dejado de ser asunto de los legisladores nacionales: por todo ello, el gravamen fiscal en virtud de derecho nacional interno sigue siendo legalmente posible de aquí en adelante. Es más, debería incluso exigírsela, dado que los excesivos pagos a tanto alzado libres de impuestos y los ingresos encubiertos que de esta manera se consiguen contradicen el principio constitucional de la justicia tributaria ${ }^{50}$, con lo que producen aun otra situación ilegal de hecho que los estados miembros, y entre ellos la República Federal de Alemania, están en la obligación de remediar.

\section{Medidas de censura contra las denuncias}

Quien se atreva a censurar públicamente alguna de las situaciones antes descritas se arriesga a ser sujeto de determinadas represalias. En vez de afrontar la crítica y eliminar los abusos, se intenta acallar a aquellos más críticos con la situación.

El eurodiputado Hans-Peter Martin, que en 1999 era todavía uno de los candidatos estrella de los socialdemócratas austriacos, fue excluido en febrero de 2004 del grupo parlamentario europeo socialdemócrata (SPE), después de haber puesto en la picota la normativa sobre dietas de estancia y reembolso de gastos de viaje (cfr. más arriba, ap. II.1 y (I.2) ${ }^{51}$. Cuando el Tribunal de Cuentas Europeo hizo constar en noviembre de 2003 que la Mesa del Parlamento no había estado facultada para aprobar el sistema de pensiones de la UE y que, por otra parte, el Tratado de la UE no proporcionaba base alguna para tal sistema, un "cuestor" intentó difamar con sus insultos a un miembro del Tribunal de Cuentas y exigió a Pat Cox, Presidente del Parlamento, que ejerciera autoridad sobre dicho Tribunal ${ }^{52}$. El corresponsal en Bruselas de la re-

49 TJE: cfr. nota 48, sec. 21.

50 Para el caso de Alemania, véase p.ej. la sentencia del Tribunal Constitucional BVerfGE 40, 296 (328).

51 Severin Weiland: «Kesseltreiben gegen EU-Abgeordneten», en Spiegel online, 12-feb-2004.

${ }^{52}$ Véase Nicola Smith: "Controversy flares over MEP pensions», en EUPolitix, 23oct-2003. 
vista Stern, Hans-Martin Tillack, citando de una lista no publicada que le había llegado por una filtración, había informado sobre las cantidades que los eurodiputados hacían ingresar a sus familiares contratándolos como colaboradores; acto seguido, por orden de la Oficina Europea de Lucha contra el Fraude (OLAF) - y en virtud de una acusación completamente distinta-, fue detenido por la policía belga, su domicilio fue registrado y confiscado su material ${ }^{53}$.

\section{MEDIDAS NECESARIAS}

Las regulaciones en vigor son insostenibles política y jurídicamente, y deben ser transformadas radicalmente:

1. En el caso de la dieta de estancia deben intensificarse las normas de demostración.

2. La cantidad global para gastos debería quedar regulada por unos índices en correspondencia con el respectivo nivel de ingresos y de precios del país de origen.

3. Hay que examinar si la dieta de estancia y la cantidad global para gastos siguen estando justificadas en las cuantías dadas hasta la fecha. En cualquier caso, no se deberá seguir abusando de ellas utilizándolas como ingresos adicionales encubiertos.

4. En los vuelos, deben reembolsarse sólo los gastos realmente habidos, y como máximo los gastos correspondientes al pasaje más caro en clase turista (abonados hasta la fecha a tanto alzado). Los viajes realizados con el automóvil propio deben, al menos, ser demostrados sin dejar lugar a equívocos. La dieta global de distancia debe ser suprimida. No hay ninguna necesidad de ella una vez que ya existen la dieta de estancia y la cantidad global por gastos.

5. El reembolso por gastos en colaboradores debe limitarse a dos de ellos, como ya se hizo durante 1993 y 1994, o bien su cuantía máxima -o en cualquier caso la parte dedicada a los colaboradores que trabajen en el país de origen-debe quedar regulada por unos índices en correspondencia con el nivel de precios y de ingresos del mismo. Debe prohibirse la colocación de familiares.

6. Especial necesidad de una modificación se da en lo relativo a las pensiones de jubilación, invalidez y para familiares. Pagar con recursos

53 «Massiver Anschlag auf die Pressefreiheit», en Stern online, 19-mar-2004. 
de la UE las enormes pensiones de los eurodiputados italianos y franceses carece de cualquier justificación. Las pensiones de jubilación son competencia de los respectivos estados miembros, como en el caso de todos los demás países. Y que existan dobles pensiones por un mismo periodo de mandato resulta completamente indefendible.

7. Por lo que respecta al procedimiento, el reembolso de costes debe quedar en su integridad regulado por un estatuto: pero un estatuto debatido públicamente en el Pleno del Parlamento, aprobado por el Consejo, sometido al dictamen de la Comisión y publicado en el Diario Oficial, tal como lo establece el art. 190 del Tratado CE.

8. Ni siquiera puede entrar en consideración que sea la Mesa la que regule las prestaciones asistenciales. Pero tampoco deberían quedar contempladas en el Estatuto. Las prestaciones asistenciales son - exactamente igual que las retribuciones- asunto de los estados miembros. Una igualación carecerá de sentido mientras subsistan la desigualdad en el derecho electoral y unos niveles de ingresos completamente diferentes en los países miembros. Esto queda demostrado por la completa desproporción en que las prestaciones ofrecidas por los sistemas de pensiones europeos se hallan respecto al nivel de ingresos de los países de la ampliación. La remuneración y las prestaciones asistenciales de los eurodiputados deberían, por tanto, ser reguladas de momento por las legislaciones nacionales, sin quedar contempladas en el Estatuto ${ }^{54}$.

\section{RESUMEN}

Libre de cualquier control efectivo, el Parlamento Europeo se ha dotado con un amplio sistema de reembolso de gastos y de pensiones que alcanza grados notablemente abusivos. En este artículo se sostiene que las regulaciones al respecto, que, en algunos caso amparan ingresos encubiertos y pensiones dobles, carecen de suficiente base jurídica y pueden contravenir varios principios del derecho comunitario.

${ }^{54}$ Véase también Von Arnim / Schurig: DVBL, 2003, 1165; Von Arnim: op. cit. en nota 9 , pp. 18 ss. 


\section{THE UNCONTROLLED GROWTH IN ALLOWANCES FOR THE MEPS.}

\section{(Abstract)}

MEPs are governed by a whole battery of rules concerning their payment and expenses which, to some extent, may be difficult to control, thus causing some anomalies, particularly those related to double pension schemes and tax arrangements for their salaries, which might contravene several Treaty provisions.

This article queries the legal basis for M.E.P.s' allowances which is regulated by the unpublished "Rules Governing the Payment of Expenses and Allowances to Members". These Rules are based solely on decisions of the Bureau of the European Parliament, a procedure hardly compatible with Art.190(5) EC, which stipulates that the financial status of Members of Parliaments is to be regulated by the Plenary of the Parliament after seeking the opinion of the Commission and with the consent of the Council. Furthermore, the "rules" facilitate a number of malpractices, which contravene several Treaty provisions. Often, the amount of reimbursed expenses is much higher than the actual expenses, and the pension systems can lead to double payments.

\section{Palabras clave}

Parlamento europeo, Estatuto de los Diputados del Parlamento Europeo, Retribuciones de los Diputados europeos, Controles financieros de la UE.

\section{Key words}

European Parliament, Statute of Members of the European Parliament, Salaries and expenses of MEPs, Financial Controlling at the EU. 